\title{
High-strength porous alumina ceramics prepared from stable wet foams
}

\author{
Linying WANG ${ }^{a, b}$, Liqiong $\mathrm{AN}^{a,{ }^{*}}$, Jin $\mathrm{ZHAO}^{b, c}$, Shunzo SHIMAI ${ }^{b}$, \\ Xiaojian MAO $^{b, c}$, Jian $Z Z_{A N G}{ }^{b, c}$, Juan $\operatorname{LIU}^{b, c}$, Shiwei WANG ${ }^{b, c, *}$ \\ ${ }^{a}$ College of Ocean Science and Engineering, Shanghai Maritime University, Shanghai 201306, China \\ ${ }^{b}$ State Key Laboratory of High Performance Ceramics and Superfine Microstructure, Shanghai Institute \\ of Ceramics, Chinese Academy of Sciences, Shanghai 200050, China \\ ${ }^{c}$ Key Laboratory of Transparent and Opto-functional Advanced Inorganic Materials, Shanghai Institute \\ of Ceramics, Chinese Academy of Sciences, Shanghai 200050, China
}

Received: December 11, 2020; Revised: March 10, 2021; Accepted: March 29, 2021

(C) The Author(s) 2021.

\begin{abstract}
Porous ceramics have been widely used in heat insulation, filtration, and as a catalyst carrier. Ceramics with high porosity and high strength are desired; however, this high porosity commonly results in low strength materials. In this study, porous alumina with high porosity and high strength was prepared by a popular direct foaming method based on particle-stabilized wet foam that used ammonium polyacrylate (PAA) and dodecyl trimethyl ammonium chloride (DTAC) as the dispersant and hydrophobic modifier, respectively. The effects of the dispersant and surfactant contents on the rheological properties of alumina slurries, stability of wet foams, and microstructure and mechanical properties of sintered ceramics were investigated. The microstructure of porous ceramics was regulated using wet foams to achieve high strength. For a given PAA content, the wet foams exhibited increasing stability with increasing DTAC content. The most stable wet foam was successfully obtained with $0.40 \mathrm{wt} \%$ PAA and $0.02 \mathrm{wt} \%$ DTAC. The corresponding porous alumina ceramics had a porosity of $82 \%$, an average grain size of $0.7 \mu \mathrm{m}$, and a compressive strength of $39 \mathrm{MPa}$. However, for a given DTAC content, the wet foams had decreasing stability with increasing PAA content. A possible mechanism to explain these results is analyzed.
\end{abstract}

Keywords: porous ceramic; alumina; dispersant; hydrophobic modifier; compressive strength

\section{Introduction}

For decades, porous ceramics have been widely used in many fields, such as heat insulation, filtration, and catalysis [1]. The properties and applications of porous

* Corresponding authors.

E-mail: L.An, anlq@shmtu.edu.cn;

S.Wang, swwang51@mail.sic.ac.cn ceramics depend on their microstructures. For example, an open-cell structure has a high specific surface area and permeability [2] that are useful for applications as catalyst carriers, molten metal filters, and bone graft materials [3]. In contrast, a closed-cell structure has low thermal conductivity that is a desirable property for thermal insulation [4-8]. Porous ceramics with high porosity and high strength are expected to be used in practical applications. Generally, porous ceramics 
with a closed-cell structure are stronger than those with an open-cell structure. However, the mechanical strength of porous ceramics decreases with their porosity, regardless of whether the cell structure is open or closed.

To obtain porous ceramics with both high porosity and high strength, the ceramics must possess a dense structure with a finer grain size and closed-cell structure with a homogeneous and small cell size. To obtain a fine grain size, a well-dispersed raw powder with a small particle size that can be sintered at a low temperature is desired. To obtain a closed-cell structure with a homogeneous and small cell size, the stability of the wet foam after direct foaming depends on the rheological properties of ceramic slurry. In addition, the slurry rheology and foam stability are closely affected by the dispersant and foaming agent. Therefore, the relationship between the additive content (dispersant and foaming agent) and foam stability is an important topic for investigation.

Recently, Zhao et al. [9] developed a simple route to fabricate porous ceramics from particle-stabilized foams involving only one dispersant and surfactant without extra additives. Particles were dispersed by an anionic dispersant and hydrophobically modified by a cationic surfactant via an electrostatic reaction between the dispersant and surfactant on the particle surface. The structure of the wet foam is stabilized by van der Waals and hydrophobic interactions among the modified particles. Therefore, factors influencing the stability of wet foam can be easily analyzed because only two additives are involved. We observed that the slurry has low viscosity at the optimal dispersant content and possesses excellent foaming ability. However, the stability of the wet foam is poor, leading to the emergence of large bubbles and a decrease in the mechanical strength of the corresponding sintered porous ceramic. Clarifying this phenomenon will enable the preparation of high-porosity ceramics with high strength. In this work, the effects of the dispersant and surfactant contents on the rheological properties of slurries, the stability of wet foams, and the microstructure and compressive strength of the resultant porous alumina were investigated. The impact of the dispersant concentration of the slurry on the wet foam stability was demonstrated, and high-porosity alumina ceramics with high strength were fabricated using fine powder and adjusting the dispersant and the surfactant content.

\section{Experimental}

\section{1 Raw material}

High-purity commercial $\alpha$-alumina powder (purity > 99.99\%, TM-DAR, Taimei Chemicals Co. Ltd., Tokyo, Japan) with an average particle size of $180 \mathrm{~nm}$ and a specific surface area of $14.3 \mathrm{~m}^{2} / \mathrm{g}$ was selected as the raw material. Ammonium polyacrylate (A-30SL, Toa gosei, Tokyo, Japan; denoted by PAA) with a molecular weight of 5000-6000 was chosen as the dispersant. Dodecyl trimethyl ammonium chloride (QUARTAMIN 24P, Kao Chemicals, Tokyo, Japan; denoted by DTAC) was used as the hydrophobic modifier. The different contents of PAA and DTAC were related to the mass of alumina powder. Deionized water was used as the solvent.

\section{2 Experimental procedures}

Alumina slurries that contained 45 vol $\%$ solids and different PAA contents were prepared in a nylon tank by stirring manually using a glass rod, and then these slurries were ball-milled at $250 \mathrm{rpm}$ for $1 \mathrm{~h}$ using alumina balls with a diameter of $5 \mathrm{~mm}$. Then, slurries with different DTAC contents were added and ball-milled for $1 \mathrm{~h}$. Subsequently, these slurries were stirred at $600 \mathrm{rpm}$ using a household stirrer for $4 \mathrm{~min}$ to obtain homogeneous wet foams. These wet foams were cast into homemade molds and dried for two days at room temperature. Finally, the green bodies were sintered at a high temperature of $1350{ }^{\circ} \mathrm{C}$ for $2 \mathrm{~h}$ and the final porous alumina ceramics were obtained.

\section{3 Characterization}

The effect of PAA on the electrochemical properties of alumina particle surfaces was measured by zeta potential analysis (NanoBrook ZetaPlus, Brookhaven Instruments, Holtsville, NY, USA). The rheological properties of slurries with different contents of PAA and DTAC were measured using a rotational rheometer (HAAKE Viscotester iQ Air, Thermo Electron GmbH, Karlsruhe, Germany) with a parallel plate $(20 \mathrm{~mm}$ in diameter) at $25{ }^{\circ} \mathrm{C}$. Adsorption of PAA to the alumina particles in the slurry was obtained as follows: First, the slurry with $45 \mathrm{vol} \%$ solids was centrifuged at $10,000 \mathrm{rpm}$ for $5 \mathrm{~min}$, and the supernatant was collected. Then, the supernatant was extracted with IPA (isopropyl alcohol) and further filtered to remove small particles. Subsequently, the PAA content in the 
supernatant was analyzed using gas chromatographymass spectrometry GC-MS (GCMS-QP2010SE, Shimadzu, Kyoto, Japan). Finally, the adsorption of PAA to the particles was obtained by comparing the PAA content in the slurry with that in the supernatant. A stability analyzer (Turbiscan Lab, Formulaction, Toulouse, France) was used to study the stability of wet foams.

The bulk density $\left(M_{\mathrm{a}}\right)$ and apparent porosity $\left(P_{\mathrm{a}}\right)$ of sintered porous ceramics were calculated based on Archimedes principle using deionized water as the immersion liquid, as follows:

$$
\begin{aligned}
& M_{\mathrm{a}}=\frac{m_{1}}{m_{2}-m_{3}} \times M_{\mathrm{w}} \\
& P_{\mathrm{a}}=\frac{m_{2}-m_{1}}{m_{2}-m_{3}}
\end{aligned}
$$

where $m_{1}, m_{2}$, and $m_{3}$ represent the dry weight, wet weight, and buoyant weight of the porous ceramics, respectively. $M_{\mathrm{w}}$ is the density of pure water.

The total porosity $(P)$ and closed porosity $\left(P_{\mathrm{c}}\right)$ can be expressed as follows:

$$
\begin{gathered}
P=1-\frac{M_{\mathrm{a}}}{M} \\
P_{\mathrm{c}}=P-P_{\mathrm{a}}
\end{gathered}
$$

where $M$ is the theoretical density of alumina $\left(3.98 \mathrm{~g} / \mathrm{cm}^{3}\right)$. The microstructure of the porous alumina ceramics was measured using scanning electron microscopy (SEM, JSM-6390LV, JEOL, Tokyo, Japan). The average cell size and size distribution were determined by measuring the diameter of 300 cells in the SEM images. The compressive strength of porous alumina ceramics was measured using cylindrical samples $9 \mathrm{~mm}$ in diameter and $17 \mathrm{~mm}$ in height using a universal testing machine (Instron5566, Instron Co., Norwood, MA, USA) with a loading rate of $0.5 \mathrm{~mm} / \mathrm{min}$. At least four samples were used to examine the compressive strength.

\section{Results and discussion}

\section{1 Effect of the PAA content on zeta potential}

The effect of the PAA content on the zeta potential on the surface of alumina particles in suspension is shown in Fig. 1. When PAA was not added, the isoelectric point $\left(\mathrm{pH}_{\mathrm{IEP}}\right)$ of the alumina particles was 7.7. The

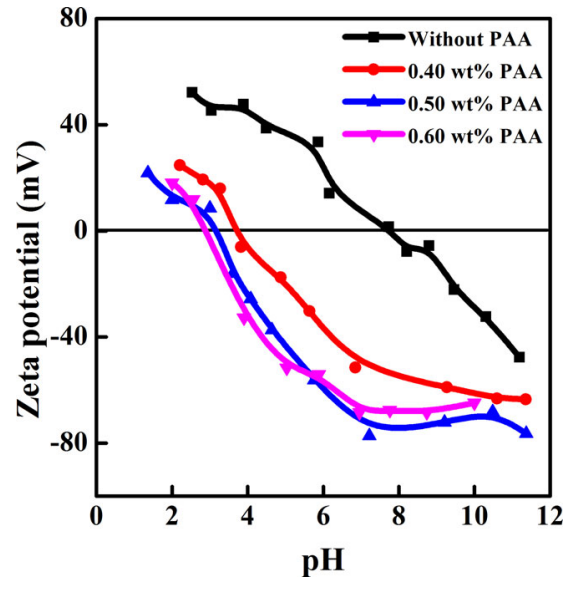

Fig. 1 Zeta potential of alumina particles with different PAA contents.

$\mathrm{pH}_{\text {IEP }}$ values of alumina particles in samples with PAA contents of $0.4,0.5$, and $0.6 \mathrm{wt} \%$, were $3.9,3.6$, and 3.4 , respectively. The surface charges of alumina particles moved in the direction of the negative potential. PAA was ionized in water and produced $\mathrm{R}-\mathrm{COO}^{-}$negatively charged groups. The negatively charged groups were adsorbed on the surface of alumina particles and neutralized the positive charges on the surface, which led to an increase in the negative charge on the surface of alumina particles. Therefore, the particles had greater electrostatic repulsion and could be dispersed stably with a higher PAA content.

\section{2 Effect of the PAA content on alumina slurry viscosity and its adsorption on alumina particles}

Figure 2 shows the effect of the PAA content on the viscosity of the prepared alumina slurries. All the slurries possessed the same shear-thinning characteristics, as is evident in Fig. 2(a). For the slurries at the same shear condition shown in Fig. 2(b), the viscosity decreased as the PAA content increased from 0.35 to $0.5 \mathrm{wt} \%$, although a peak was present at $0.45 \mathrm{wt} \%$ PAA. This result is consistent with that reported by Davies and Binner [10]. According to Davies and Binner's explanation, the PAA content at $0.45 \mathrm{wt} \%$ in this study was close to the critical value. At this point, most of the separated PAA molecular chains were adsorbed on alumina particles, so an increase in the free $\mathrm{NH}_{4}^{+}$ion concentration from the dissociation process would reduce the electrostatic repulsion among particles and lead to an increase in slurry viscosity. When the PAA content exceeded this critical value $(>0.45 \mathrm{wt} \%)$, an 

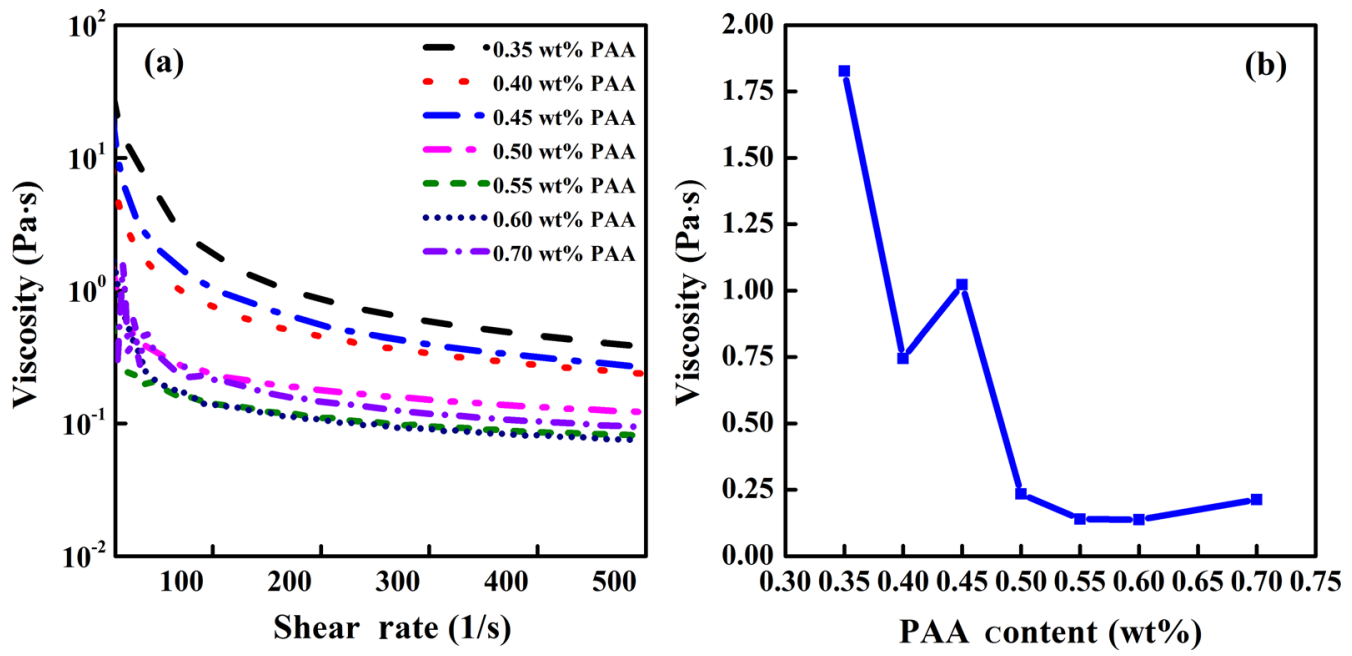

Fig. 2 Viscosity of alumina slurries versus shear rate (a) and PAA content (b) at the shear rate of $100 \mathrm{~s}^{-1}$.

excessive amount of PAA was free in the slurry and adsorbed or multiple wound on the alumina particle surface, resulting in an increase in the electrostatic repulsion among particles, and the observed decrease in slurry viscosity.

When the PAA content was increased to 0.55 and $0.60 \mathrm{wt} \%$, the viscosity was the lowest. This result implies that the slurry has an optimal addition amount from 0.55 to $0.60 \mathrm{wt} \%$ PAA. However, the adsorption capacity that is shown in Fig. 3 indicates the actual amount of PAA adsorption on the particles gradually deviated from the ideal adsorption curve with increasing PAA content. This result indicates an increase in free PAA in the slurry. Free PAA in the slurry can exist in three configurations: straight, cyclically curved, and multiple remnants. When the PAA content increases, the configuration of the free PAA molecular chain

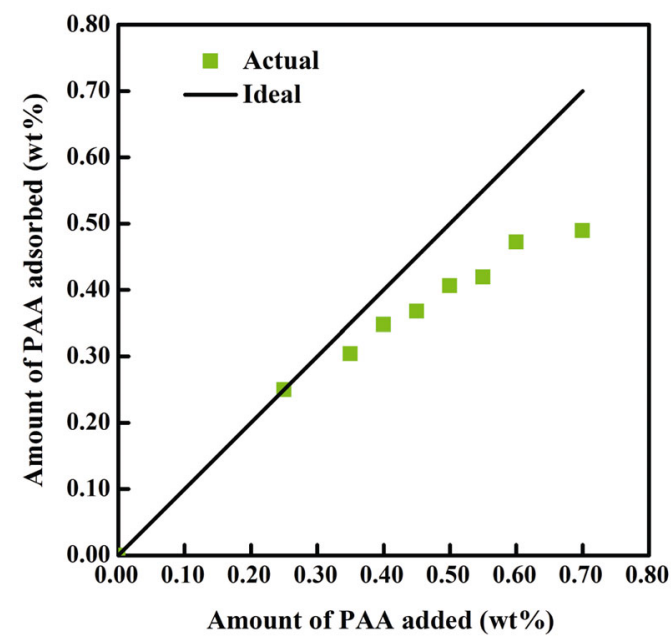

Fig. 3 Amount of PAA adsorbed on the alumina particles compared with that added in the slurry. changes from straight to curved ring and multiple remnants [10]. Some free PAA is entangled with the PAA molecular chain adsorbed on the particles, and so the negative charge on the particle surface and electrostatic repulsion among particles is increased, resulting in a decrease in the viscosity of the slurry. These free and adsorbed PAA molecules affect the rheological properties of alumina slurries and the stability of wet foam. Therefore, the viscosity of alumina slurries and the actual amount of PAA adsorption on the alumina particles should be considered together to determine the optimal PAA content.

\section{3 Effect of the PAA and DTAC contents on rheological properties}

Figure 4 shows the viscosities of alumina slurries with

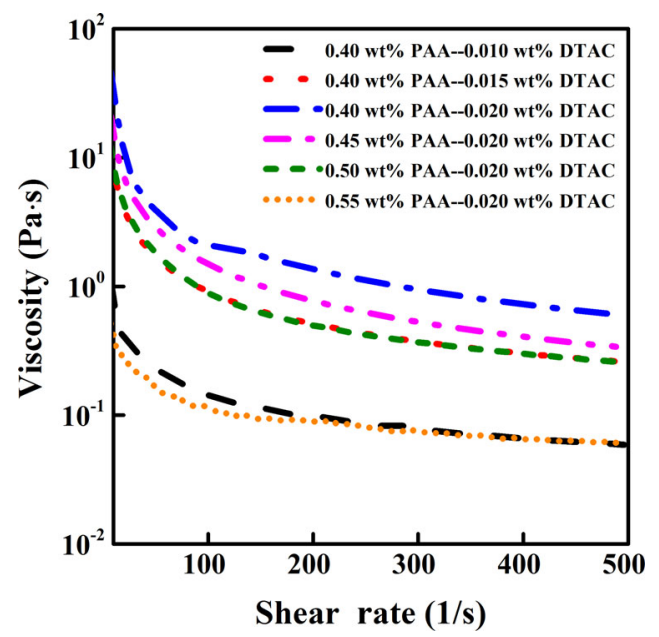

Fig. 4 Effect of the PAA and DTAC contents on the viscosity of alumina slurries. 
different PAA and DTAC contents. All the alumina slurries exhibited shear-thinning characteristics. For a fixed PAA content of $0.40 \mathrm{wt} \%$, the viscosity of the alumina slurry at a shear rate of $100 \mathrm{~s}^{-1}$ decreased initially from 0.74 to $0.15 \mathrm{~Pa} \cdot \mathrm{s}$ as the DTAC content increased from 0 to $0.010 \mathrm{wt} \%$, but DTAC contents of 0.015 and $0.020 \mathrm{wt} \%$ had increased viscosities of 0.9 and $2.1 \mathrm{~Pa} \cdot \mathrm{s}$, respectively. DTAC added to the slurry combines with PAA, decreasing the surface charge of the particles. The electrostatic repulsion among particles is decreased and the hydrophobic effect is enhanced, leading to an increase in the mutual attraction among particles and agglomeration of these particles. Hence, the viscosity of the slurry increased. For a fixed DTAC content of $0.020 \mathrm{wt} \%$, the viscosities of the slurries with PAA contents that ranged from 0.40 to $0.55 \mathrm{wt} \%$ decreased steadily from 2.1 to $0.1 \mathrm{~Pa} \cdot \mathrm{s}$ at $100 \mathrm{~s}^{-1}$. This result could be due to an increase in free PAA in the slurry with increasing PAA content. Free PAA in the slurry would inevitably interact with DTAC, leading to a decrease in the amount of DTAC adsorbed on the particles. Therefore, the viscosities of these slurries were influenced by PAA rather than by DTAC.

Figure 5 shows the storage modulus of alumina slurries with different PAA and DTAC contents. When the PAA content was fixed at $0.4 \mathrm{wt} \%$, the storage modulus of the slurry with $0.010 \mathrm{wt} \%$ DTAC did not change significantly during the entire time range, whereas that of the slurry with $0.020 \mathrm{wt} \%$ DTAC increased gradually with time, indicating that gelation occurred. The increase in the DTAC contents results in an attenuation of electrostatic repulsion among particles and an increase in hydrophobic interactions that leads to an increase in the interaction among particles in the

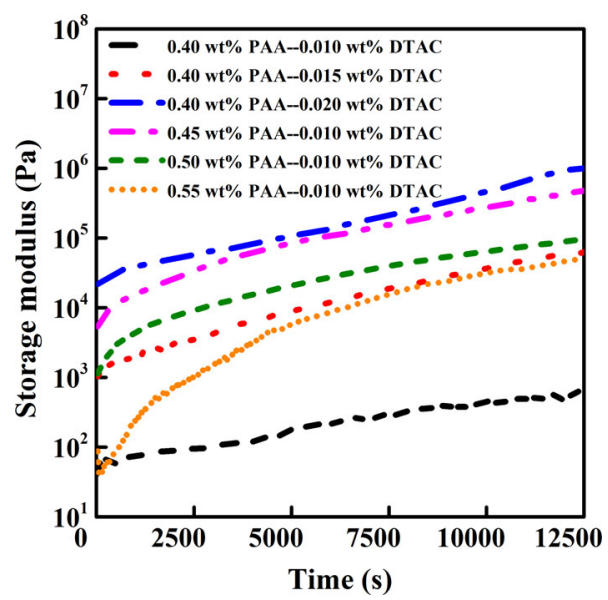

Fig. 5 Effect of the PAA and DTAC contents on the storage modulus of alumina slurries. presence of hydrophobic and van der Waals interactions. Thus, the storage modulus of the slurry increased. In contrast, when the DTAC content was fixed at $0.020 \mathrm{wt} \%$, the storage modulus of the slurries decreased as the amount of PAA increased from 0.40 to $0.55 \mathrm{wt} \%$. Weaker interaction among particles was observed at higher PAA contents because of increased electrostatic repulsion and decreased hydrophobic interactions.

\section{4 Effect of the PAA and DTAC contents on foam stability}

A stability analyzer is based on the principle of multi-gravity light scattering, and this technique has been used to measure the stability of various aqueous foams [11]. Wet foam was added to a cylindrical transparent quartz glass bottle with an inner diameter of $25.5 \mathrm{~mm}$ and a height of $45 \mathrm{~mm}$, and infrared light $(880 \mathrm{~nm})$ was used as the incident source. Backscattered light (BS) at an angle of $45^{\circ}$ to the incident light was monitored by an optical detector, as shown in Fig. 6 . The changes in the backscatter signal were recorded as follows: The first scan was the benchmark used as the background for the subsequent scans of samples that were performed layer by layer at an interval of $40 \mu \mathrm{m}$. The signal values obtained from the samples were subtracted from the background value and labeled as $\triangle B S$. A negative $\triangle B S$ value indicates growth of the bubble size of the foam. A larger absolute $\triangle B S$ value indicates coarsening of the foam. The stability of the wet foam can be analyzed comprehensively by comparing the changes in $\triangle B S$ at different scanning time.

Figure 7 shows the variation in $\triangle B S$ of foams prepared from alumina slurries with different PAA and DTAC contents. All the samples exhibited a downward trend in this value over time. When the PAA content was fixed at $0.40 \mathrm{wt} \%$, the absolute $\triangle B S$ decreased with the increase in the amount of DTAC, indicating an enhancement in the stability of the wet foam. When the

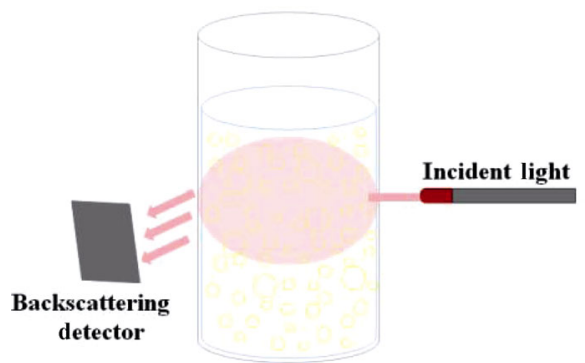

Fig. 6 Schematic diagram of a Turbiscan stability analyzer for wet foam stability measurement. 


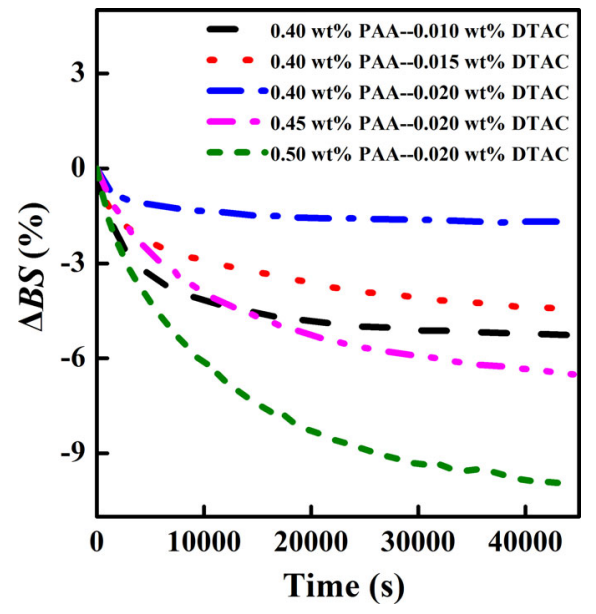

Fig. $7 \quad \triangle B S$ of wet alumina foams with different PAA and DTAC contents.

DTAC content was $0.020 \mathrm{wt} \%$, the absolute $\Delta B S$ was the smallest. This smallest value means that this foam was the most stable. When the DTAC content was further increased to $0.025 \mathrm{wt} \%$, the slurry flocculated easily during the ball milling process, leading to a failed foaming process. When the DTAC content was fixed at $0.020 \mathrm{wt} \%$, the absolute $\triangle B S$ increased with increasing PAA content, indicating a decrease in the stability of the wet foam. The most stable wet foam was obtained using $0.40 \mathrm{wt} \%$ PAA and $0.020 \mathrm{wt} \%$ DTAC. These results show that the stability of wet foam can be tailored by adjusting the PAA and DTAC contents that play crucial roles in the subsequent performance of porous ceramics.

\section{5 Effect of the PAA and DTAC contents on the microstructure, porosity, and compressive strength of porous alumina ceramics}

Figure 8 shows the SEM images of the porous alumina ceramics with different PAA and DTAC contents. These images shows gradual decrease of the cell size and the cell size distribution becomes uniform with an increase in the DTAC content when the PAA content is $0.40 \mathrm{wt} \%$ (Figs. $8(\mathrm{a})-8(\mathrm{c})$ ). When the DTAC content is $0.020 \mathrm{wt} \%$, the number of large cells gradually increases, and the cell size distribution becomes heterogeneous with an increase in PAA content (Figs. $8(\mathrm{c})-8(\mathrm{f}))$. The cell size distribution of porous alumina with $0.40 \mathrm{wt} \%$ PAA and $0.020 \mathrm{wt} \%$ DTAC is the smallest and most uniform. The inset in Fig. 8(c) exhibits a relatively uniform, dense microstructure with small grains $(0.7 \mu \mathrm{m})$ at the pore wall of the porous ceramics.

Table 1 shows the porosity and compressive strength of the porous ceramics after sintering at $1350{ }^{\circ} \mathrm{C}$ for $2 \mathrm{~h}$. When the PAA content was fixed at $0.40 \mathrm{wt} \%$ and the amount of DTAC increased from 0.010 to $0.020 \mathrm{wt} \%$, the porosity of the porous ceramics decreased slightly whereas the closed porosity increased from $33 \%$ to $75 \%$. The average cell size decreased from $129 \pm 124$ to $64 \pm 21 \mu \mathrm{m}$, whereas the compressive strength increased from 19 to $39 \mathrm{MPa}$. When the amount of DTAC was fixed at $0.020 \mathrm{wt} \%$ and the amount of PAA was increased from 0.40 to $0.55 \mathrm{wt} \%$, the porosity of the
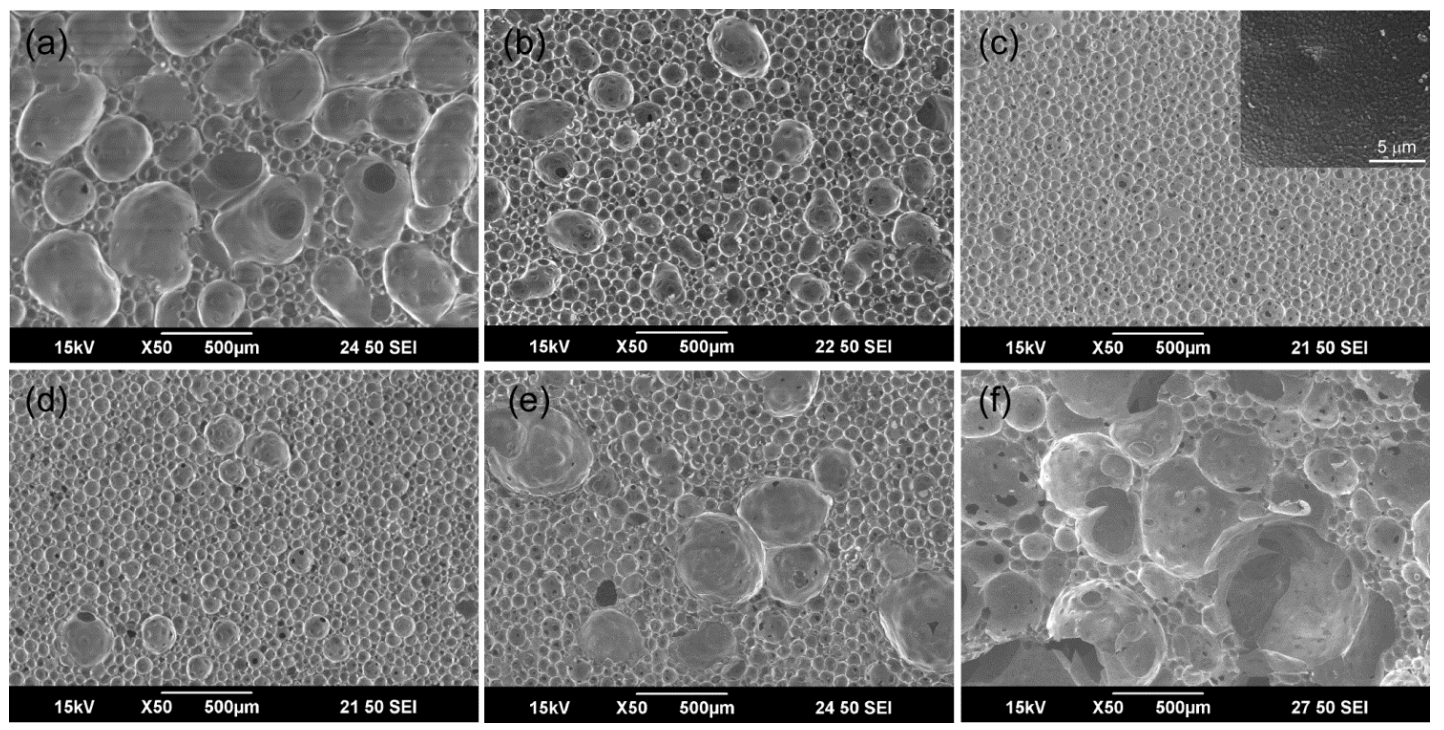

Fig. 8 SEM micrographs of porous alumina ceramics with different PAA and DTAC contents: (a) $0.40 \mathrm{wt} \%$ PAA-0.010 wt $\%$ DTAC, (b) $0.40 \mathrm{wt} \%$ PAA-0.015 wt $\%$ DTAC, (c) $0.40 \mathrm{wt} \%$ PAA- $0.020 \mathrm{wt} \%$ DTAC, (d) $0.45 \mathrm{wt} \%$ PAA- $-0.020 \mathrm{wt} \%$ DTAC, (e) $0.50 \mathrm{wt} \%$ PAA- $-0.020 \mathrm{wt} \%$ DTAC, and (f) $0.55 \mathrm{wt} \%$ PAA- $0.020 \mathrm{wt} \%$ DTAC. The inset in (c) shows grains in the cell wall. 
Table 1 Porosity, cell size, and compressive strength of porous alumina ceramics

\begin{tabular}{ccccccc}
\hline Number of samples & PAA $(\mathrm{wt} \%)$ & DTAC $(\mathrm{wt} \%)$ & Total porosity $(\%)$ & Closed porosity $(\%)$ & Cell size $(\mu \mathrm{m})$ & Compressive strength $(\mathrm{MPa})$ \\
\hline P40D10 & 0.40 & 0.010 & 85 & 33 & $129 \pm 124$ & $18.5 \pm 1.0$ \\
P40D15 & 0.40 & 0.015 & 86 & 75 & $81 \pm 41$ & $25.1 \pm 2.7$ \\
P40D20 & 0.40 & 0.020 & 82 & 75 & $64 \pm 21$ & $39.0 \pm 3.8$ \\
P45D20 & 0.45 & 0.020 & 80 & 73 & $64 \pm 23$ & $37.7 \pm 6.0$ \\
P50D20 & 0.50 & 0.020 & 81 & 64 & $92 \pm 64$ & $20.5 \pm 1.8$ \\
P55D20 & 0.55 & 0.020 & 86 & 11 & $162 \pm 162$ & - \\
\hline
\end{tabular}

porous ceramics increased slightly from $82 \%$ to $86 \%$, average pore size increased from $64 \pm 21$ to $162 \pm 162 \mu \mathrm{m}$, and compressive strength decreased from 39 to $21 \mathrm{MPa}$.

The porosity and cell size are mainly determined by the rheological properties of the slurry and the stability of the wet foam, which depend on the solid content [12], PAA content, and DTAC content of the slurry [9]. A PAA content that is too low affects the dispersion of alumina particles and causes the failure of subsequent foaming. Excessive PAA leads to an increase in free PAA in the slurry that reduces the efficiency of hydrophobic modification by DTAC on the particles and further affects the stability of the wet foam; specifically, unstable bubbles grow or break easily during the drying process. Finally, the size of the pores increased and the cell size distribution was uneven. At an appropriate PAA content, increasing the DTAC content can improve the slurry viscosity and storage modulus, enhancing the stability of the wet foam and leading to a small change in foam growth during the drying process. Finally, the size of the ceramic pores was small and evenly distributed.

The compressive strength of porous ceramics is greatly affected by their porosity, closed porosity, and cell size. Moreover, small grains are beneficial to the cell wall structure and enhance the compressive strength of porous ceramics. When the amounts of PAA and DTAC were 0.40 and $0.020 \mathrm{wt} \%$, respectively, the compressive strength of the porous ceramics, average pore diameter, total porosity, and closed porosity were $39 \mathrm{MPa}, 64 \pm 21 \mu \mathrm{m}, 82 \%$, and $75 \%$, respectively. The compressive strength and porosity of the samples prepared in this study were higher than those reported in the literature, as shown in Table 2. This result is mainly ascribed to the fine, homogenous closed cells, as shown in Fig. 8 and summarized in Table 1. A similar observation has been reported in high-strength porous alumina [9] and mullite ceramics [18]. In this study, the wet foam with $0.40 \mathrm{wt} \%$ PAA and $0.020 \mathrm{wt} \%$ DTAC exhibited the highest stability
Table 2 Properties of porous alumina ceramics prepared via different methods

\begin{tabular}{lccc}
\hline \multicolumn{1}{c}{ Method } & $\begin{array}{c}\text { Porosity } \\
(\%)\end{array}$ & $\begin{array}{c}\text { Compressive } \\
\text { strength } \\
(\mathrm{MPa})\end{array}$ & $\begin{array}{c}\text { Average cell } \\
\text { size }(\mu \mathrm{m})\end{array}$ \\
\hline $\begin{array}{l}\text { Direct forming method in the } \\
\text { present work }\end{array}$ & 82 & 39 & 64 \\
$\quad$ Direct foaming method [13] & 64 & 57 & - \\
Particle-stabilized foam [9] & 80 & 30 & 50 \\
Sacrificial template method [14] & 70 & 28 & 370 \\
Tert-butanol gel casting [15] & $57-62$ & 28 & - \\
Particle-stabilized foam [16] & 65 & 25 & 57 \\
Particle-stabilized foam [17] & 65 & $27-14$ & $100-150$ \\
\hline
\end{tabular}

(Fig. 7). The microstructure of the wet foam was well maintained without severe coalescence and coarsening during drying, and a homogenous microstructure with fine closed cells consisting of small pores and uniform pore distribution was observed in the sintered porous ceramics (Fig. 8(c)). Smaller grains lead to higher compressive strengths of the dense polycrystalline ceramics. Fine alumina powder was used as the starting material, so dense cell walls with small grains were observed that improved the compressive strength, as shown in Fig. 8(c) inset. Therefore, porous alumina with a porosity of $82 \%$ and compressive strength of 39 MPa was successfully fabricated.

\section{Conclusions}

The effects of the dispersant PAA and surfactant DTAC on the rheological properties of alumina slurries, stability of wet foams, and microstructure and mechanical properties of sintered ceramics were studied. DTAC hydrophobically modified the surface of alumina dispersed by PAA, and the combination of PAA and DTAC played an important role in the stability of wet foam. Free PAA affected the subsequent foam stability by increasing the coarsening of wet foam, which led to an increase in the average 
cell size of the porous ceramics by occupying part of the DTAC molecule. An effective method to prepare high-porosity alumina ceramics with high strength was to adjust the proportions of PAA and DTAC. When the amounts of PAA and DTAC were 0.40 and $0.020 \mathrm{wt} \%$, the prepared porous alumina ceramic had an average cell size of $64 \mu \mathrm{m}$, a porosity of $82 \%$, and a compressive strength of $39 \mathrm{MPa}$.

\section{Acknowledgements}

This research was supported by the National Natural Science Foundation of China (51602194 and 51772309), and Science Foundation for Youth Scholar of State Key Laboratory of High Performance Ceramics and Superfine Microstructures (SKL201901).

\section{References}

[1] Chen Y, Wang NN, Ola O, et al. Porous ceramics: Light in weight but heavy in energy and environment technologies. Mat Sci Eng R 2021, 143: 100589.

[2] Li H, Liu YS, Liu YS, et al. Silica strengthened alumina ceramic cores prepared by $3 \mathrm{D}$ printing. J Eur Ceram Soc 2021, 41: 2938-2947.

[3] Elsayed H, Colombo P, Crovace MC, et al. Suitability of Biosilicate ${ }^{\circledR}$ glass-ceramic powder for additive manufacturing of highly porous scaffolds. Ceram Int 2021, 47: 82008207.

[4] Gonzenbach UT, Studart AR, Tervoort E, et al. Ultrastable particle-stabilized foams. Angew Chem Int Ed 2006, 45: 3526-3530.

[5] Gonzenbach UT, Studart AR, Steinlin D, et al. Processing of particle-stabilized wet foams into porous ceramics. $\mathrm{J} \mathrm{Am}$ Ceram Soc 2007, 90: 3407-3414.

[6] Sepulveda P, Binner JGP. Processing of cellular ceramics by foaming and in situ polymerisation of organic monomers. J Eur Ceram Soc 1999, 19: 2059-2066.

[7] Studart AR, Gonzenbach UT, Tervoort E, et al. Processing routes to macroporous ceramics: A review. J Am Ceram Soc 2006, 89: 1771-1789.

[8] Hammel EC, Ighodaro OLR, Okoli OI. Processing and properties of advanced porous ceramics: An application based review. Ceram Int 2014, 40: 15351-15370.

[9] Zhao J, Shimai S, Zhou GH, et al. Ceramic foams shaped by oppositely charged dispersant and surfactant. Colloid Surfaces A 2018, 537: 210-216.

[10] Davies J, Binner JGP. The role of ammonium polyacrylate in dispersing concentrated alumina suspensions. $J$ Eur Ceram Soc 2000, 20: 1539-1553.

[11] Zhao J, Yang C, Shimai S, et al. The effect of wet foam stability on the microstructure and strength of porous ceramics. Ceram Int 2018, 44: 269-274.

[12] Wang SJ, Yang ZH, Duan XM, et al. Fabrication and characterization of in situ porous $\mathrm{Si}_{3} \mathrm{~N}_{4}-\mathrm{Si}_{2} \mathrm{~N}_{2} \mathrm{O}-\mathrm{BN}$ ceramic. Int J Appl Ceram Technol 2014, 11: 832-838.

[13] Tang XY, Zhang ZJ, Zhang XY, et al. Design and formulation of polyurethane foam used for porous alumina ceramics. J Polym Res 2018, 25: 136.

[14] Zhang MW, Li XD, Zhang M, et al. High-strength macro-porous alumina ceramics with regularly arranged pores produced by gel-casting and sacrificial template methods. J Mater Sci 2019, 54: 10119-10129.

[15] Liu RP, Li YT, Wang CG, et al. Fabrication of porous alumina-zirconia ceramics by gel-casting and infiltration methods. Mater Des 2014, 63: 1-5.

[16] Sciamanna V, Nait-Ali B, Gonon M. Mechanical properties and thermal conductivity of porous alumina ceramics obtained from particle stabilized foams. Ceram Int 2015, 41: 2599-2606.

[17] Tallon C, Chuanuwatanakul C, Dunstan DE, et al. Mechanical strength and damage tolerance of highly porous alumina ceramics produced from sintered particle stabilized foams. Ceram Int 2016, 42: 8478-8487.

[18] Ren JT, Ying W, Zhao J, et al. High-strength porous mullite ceramics fabricated from particle-stabilized foams via oppositely charged dispersants and surfactants. Ceram Int 2019, 45: 6385-6391.

Open Access This article is licensed under a Creative Commons Attribution 4.0 International License, which permits use, sharing, adaptation, distribution and reproduction in any medium or format, as long as you give appropriate credit to the original author(s) and the source, provide a link to the Creative Commons licence, and indicate if changes were made.

The images or other third party material in this article are included in the article's Creative Commons licence, unless indicated otherwise in a credit line to the material. If material is not included in the article's Creative Commons licence and your intended use is not permitted by statutory regulation or exceeds the permitted use, you will need to obtain permission directly from the copyright holder.

To view a copy of this licence, visit http://creativecommons.org/licenses/by/4.0/. 